\title{
Population-Based Study on Risk Factors for Tumor-Positive Resection Margins in Patients with Gastric Cancer
}

\author{
Leonie R. van der Werf, MD ${ }^{1}$ (D), Charlotte Cords, MD $^{1}$, Ivo Arntz, MD, PhD ${ }^{2}$, Eric J. T. Belt, MD, PhD ${ }^{3}$, \\ Ivan M. Cherepanin, $\mathrm{MD}, \mathrm{PhD}^{2}$, Peter-Paul L. O. Coene, $\mathrm{MD}, \mathrm{PhD}^{4}$, Erwin van der Harst, $\mathrm{MD} \mathrm{PhD}^{4}$, \\ Joos Heisterkamp, MD, $\mathrm{PhD}^{5}$, Barbara S. Langenhoff, $\mathrm{MD}, \mathrm{PhD}^{5}$, Bas Lamme, $\mathrm{MD}, \mathrm{PhD}^{3}$, \\ Mark I. van Berge Henegouwen, MD, $\mathrm{PhD}^{6}$, Sjoerd M. Lagarde, MD, $\mathrm{PhD}^{1}$, and Bas P. L. Wijnhoven, MD, $\mathrm{PhD}^{1}$ \\ ${ }^{1}$ Department of Surgery, Erasmus University Medical Centre Rotterdam, Rotterdam, The Netherlands; ${ }^{2}$ Department of \\ Surgery, Bravis Hospital, Roosendaal, The Netherlands; ${ }^{3}$ Department of Surgery, Albert Schweitzer Hospital, Dordrecht, \\ The Netherlands; ${ }^{4}$ Department of Surgery, Maasstad Hospital, Rotterdam, The Netherlands; ${ }^{5}$ Department of Surgery, \\ Elisabeth Tweesteden Hospital, Tilburg, The Netherlands; ${ }^{6}$ Department of Surgery, Cancer Center Amsterdam, Academic \\ Medical Centre, University of Amsterdam, Amsterdam, The Netherlands
}

\begin{abstract}
Background. Radical gastrectomy is the cornerstone of the treatment of locally advanced gastric cancer. This study was designed to evaluate factors associated with a tumorpositive resection margin after gastrectomy and to evaluate the influence of hospital volume.

Methods. In this Dutch cohort study, patients with junctional or gastric cancer who underwent curative gastrectomy between 2011 and 2017 were included. The primary outcome was incomplete tumor removal after the operation defined as the microscopic presence of tumor cells at the resection margin. The association of patient and disease characteristics with incomplete tumor removal was tested with multivariable regression analysis. The association of annual hospital volume with incomplete tumor removal was tested and adjusted for the patient- and disease characteristics.
\end{abstract}

Results. In total, 2799 patients were included. Incomplete tumor removal was seen in $265(9.5 \%)$ patients. Factors associated with incomplete tumor removal were: tumor located in the entire stomach (odds ratio (OR) [95\%

Electronic supplementary material The online version of this article (https://doi.org/10.1245/s10434-019-07381-0) contains supplementary material, which is available to authorized users.

(C) The Author(s) 2019

First Received: 29 January 2019;

Published Online: 22 April 2019

L. R. van der Werf, MD

e-mail: 1.r.vdwerf@gmail.com confidence interval (CI): 3.38 [1.91-5.96] reference: gastroesophageal junction), cT3, cT4, cTx (1.75 [1.20-2.56], 2.63 [1.47-4.70], 1.60 [1.03-2.48], reference: cT0-2), $\mathrm{pN}+$ (2.73 [1.96-3.80], reference: $\mathrm{pN}-$ ), and diffuse and unknown histological subtype (3.15 [2.14-4.46] and 2.05 [1.34-3.13], reference: intestinal). Unknown differentiation grade was associated with complete tumor removal $(0.50$ [0.30-0.83], reference: poor/undifferentiated). Compared with a hospital volume of $<20$ resections/year, 20-39, and $>39$ resections were associated with lower probability for incomplete tumor removal (OR $0.56[0.42-0.76]$ and 0.34 [0.18-0.64]).

Conclusions. Tumor location, cT, pN, histological subtype, and tumor differentiation are associated with incomplete tumor removal. The association of incomplete tumor removal with an annual hospital volume of $<20$ resections may underline the need for further centralization of gastric cancer care in the Netherlands.

A radical gastrectomy is one of the most important predictors of survival in patients with gastric cancer. ${ }^{1}$ An nonradical resection, i.e., gastrectomy with a tumor-positive resection margin (incomplete tumor removal), is seen in approximately $1.8-8.4 \%$ of patients. ${ }^{2}$ In the Netherlands, the percentage of incomplete tumor removal is used as one of the quality indicators of gastrectomies. Between 2011 and 2016, of all gastrectomies for gastric cancer with curative intent, in $9-13 \%$ the tumors were incompletely removed. ${ }^{3}$ This number corresponds with other European outcome registries. ${ }^{4,5}$ The British National Oesophago- 
Gastric Cancer Audit (NOGCA) reported that up to $29 \%$ of the gastrectomies performed in individual hospitals had tumor-positive margins. ${ }^{5}$ In the Swedish Register for Esophageal and Gastric Cancer (NREV), the percentage of incomplete tumor removal/unknown resection status was $17 \%$. $^{4}$

Gastric cancer surgery might involve tumor-positive margins on the distal side (duodenum), proximal (gastric remnant or esophagus), or circumferential. With the current literature, it is unknown which side is most involved. The Dutch national guideline, nevertheless, recommends a proximal and distal resection margin of $60 \mathrm{~mm} .^{6}$

Awareness of increased risk for incomplete tumor removal may prevent this undesirable outcome. However, data on factors associated with incomplete tumor removal, including preoperative risk assessment models, are scarce. So far, retrospective studies have reported on cohorts from single centers, and only few patients were included., ${ }^{2,7}$ Also, surgical expertise and quality assurance may play an important role. Because individual surgical volume data are difficult to retrieve, annual hospital volume is a widely accepted proxy for surgical experience. For complex surgery, including upper gastrointestinal surgery, there is evidence that higher hospital volume and individual surgeon volume are associated with improved surgical quality and outcome. ${ }^{8-11}$ However, the relation between hospital volume and incomplete tumor removal has never been investigated.

This study was designed to evaluate the factors associated with incomplete tumor removal in a Dutch cohort. Furthermore, we sought the association between hospital volume and incomplete tumor removal.

\section{METHODS}

\section{Study Design}

Patient data were retrieved from the Dutch Upper Gastrointestinal Cancer Audit. This surgical audit was initiated in 2011. Hospitals are mandated to register all patients with esophageal or gastric cancer undergoing surgery with curative intent. The DUCA provides insight into the quality of care by reporting validated process and outcome parameters, defined as "quality indicators."

Because the radicality of an operation is used as one of the quality indicators, the resection status $(R 0, R 1, R 2$, not applicable, or unknown), as well as the site of the resection margin (proximal, distal, circumferential) in millimeters is registered. For the reporting of the pathological examination of esophageal and gastric cancer, a standardized report is used. ${ }^{12}$ For this study, data on pathology of the resection specimen, patient, tumor, and treatment characteristics were used. Validation of completeness and accuracy of data registration in the DUCA dataset has been performed. ${ }^{13}$ Patient- and hospital identity is anonymous in this database. The study protocol was approved by the DUCA scientific committee.

\section{Patient Selection}

Included were all patients with gastric cancer or cancer of the esophagogastric junction (Siewert type I-III) who underwent gastrectomy between 2011 and 2017 defined as curative by the surgeon at the end of the operation. ${ }^{14}$ Patients were excluded if the resection status or essential elements of the registration were unknown including date of birth, survival status at 30 days after surgery or date of discharge (in case of a hospital stay of $>30$ days).

\section{Outcomes}

The primary outcome was complete tumor removal as documented by the pathologist based on examination of the resection specimen. The definition of the College of American Pathologists is used in the DUCA to define the completeness of the tumor removal. ${ }^{15}$ Removal of the tumor is considered complete $(R 0)$ if no microscopical tumor cells are visible in the margin and incomplete $(R 1$ or $R 2$ ) if microscopically or macroscopically tumor cells are visible in the margin. (Patients whom the surgeon defined the resection as complete and curative at the end of the operation, but where the pathological examination showed an $R 2$ resection, were included, because this study focuses on the surgeon's estimation of the resection margins.)

\section{Statistical Analysis}

To compare patient and tumor characteristics between the groups with an $R 0$ and $R 1 / R 2$ resection, the $\chi^{2}$ test was used. Univariable and multivariable logistic regression analyses were performed to identify factors associated with incomplete tumor removal. Factors with a $P$ value $<0.10$ in univariable analyses or with clinical relevance were included in the multivariable analyses. To test whether the explanatory variables are useful in predicting the outcome, the Nagelkerke $R^{2}$ and an area under the receiver operating characteristic curve (ROC) was used. By expert opinion, possible factors for the preoperative associated risk model were selected. At the selection of factors for this model, it was decided to choose only patient and tumor characteristics. Treatment characteristics, such as neo-adjuvant chemotherapy and surgical approach, were not selected. Because this could potentially lead to bias, these factors were analysed with descriptive statistics. The factors' age, Charlson comorbidity score, American Society of 
Anesthesiologists (ASA) score, tumor location, TNM stage, histological subtype, differentiation grade, and year of surgery were used. ${ }^{16}$ To determine factors that can be used preoperatively to identify patients who are at risk for incomplete tumor removal, the clinical TNM category was preferred for this analysis. However, for N-status of the tumor it was chosen to use $\mathrm{pN}$-stage. The first reason was because an unknown clinical N-stage $(\mathrm{cNx})$ was registered in $13 \%$ of patients. ${ }^{17}$ Also, $\mathrm{cN}$-stage and $\mathrm{pN}$-stage do often not correspond, and pN-stage is more reliable.

To test the association of annual hospital volume with the resection status, logistic regression models were used with and without adjustment for case-mix variety. Because centralization has taken place in the Netherlands, analyses were executed in the total cohort of 2011-2017 and stratified for the most recent years 2014-2017. Between 2014 and 2017 hospital volumes were more constant. To address possible confounding caused by differences in treatment strategy between high- and low-volume hospitals, stratified analyses for patients treated with or without neo-adjuvant therapy was performed.

The annual hospital volume in the year of surgery was assigned to each patient. Because the minimum annual hospital volume in the Netherlands is 20 resections per year and to draw clinically relevant conclusions, subsequently, the volume was grouped into three groups: $<20,20-39$, and $\geq 40$ resections per year. Missing items were analyzed in a separate group if exceeding $5 \%$.

For all analyses, statistical significance was defined as $P<0.05$. All analyses were performed with SPSS version 24 (IBM, Armonk, NY).

\section{RESULTS}

A total of 2799 patients had undergone a curative gastrectomy according to the surgeon at the end of the operation and met the inclusion criteria (Fig. 1). The majority of patients were male $(63 \%)$, and the median age
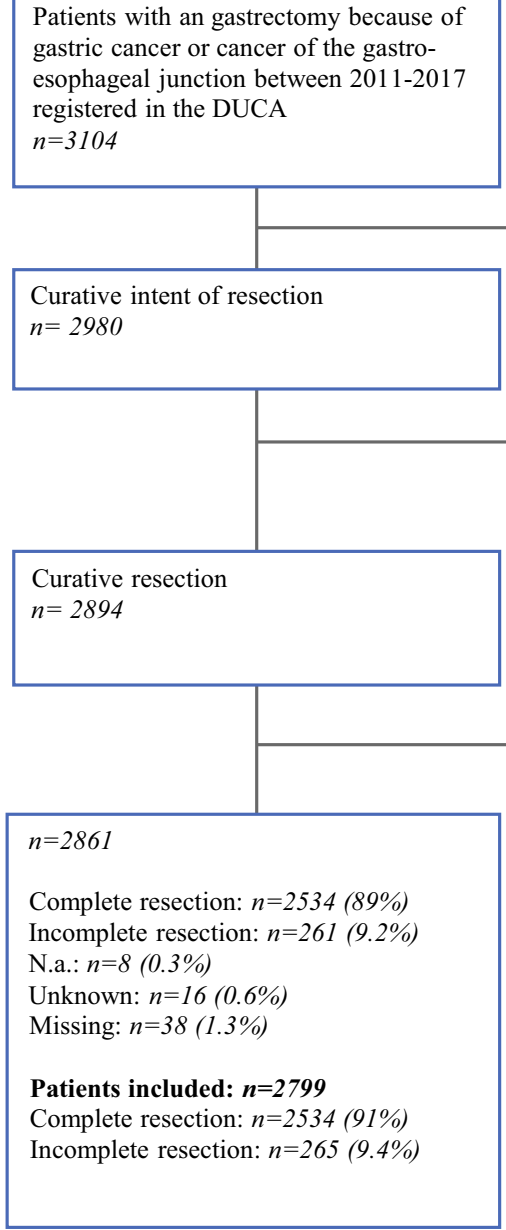

Patients excluded because:

No curative intent:

Palliative $n=92$

Prophylactic $n=14$

Unknown intent $n=18$

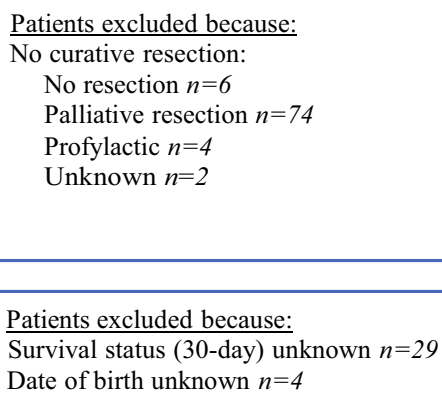

FIG. 1 Flowchart inclusion 
TABLE 1 Patient and tumor characteristics

\begin{tabular}{|c|c|c|c|c|c|c|c|}
\hline \multirow[t]{3}{*}{ Patient characteristics } & \multirow{2}{*}{\multicolumn{2}{|c|}{$\begin{array}{l}\text { Total } \\
n=2799\end{array}$}} & \multirow{2}{*}{\multicolumn{2}{|c|}{$\begin{array}{l}\text { Complete tumor removal } \\
n=2534(90.5 \%)\end{array}$}} & \multirow{2}{*}{\multicolumn{2}{|c|}{$\begin{array}{l}\text { Incomplete tumor removal } \\
n=265(9.5 \%)\end{array}$}} & \multirow[t]{3}{*}{$P$ value } \\
\hline & & & & & & & \\
\hline & $n$ & $\%$ & $n$ & $\%$ & $n$ & $\%$ & \\
\hline \multicolumn{7}{|l|}{ Gender } & 0.044 \\
\hline Man & 1754 & 63 & 1603 & 63 & 151 & 57 & \\
\hline Women & 1045 & 37 & 931 & 37 & 114 & 43 & \\
\hline \multicolumn{7}{|l|}{ Age (in groups) } & 0.142 \\
\hline$<65$ years & 888 & 32 & 791 & 31 & 97 & 37 & \\
\hline $65-74$ years & 959 & 34 & 880 & 35 & 79 & 30 & \\
\hline$>75$ years & 952 & 34 & 863 & 34 & 89 & 34 & \\
\hline \multicolumn{7}{|l|}{ Charlson score } & 0.119 \\
\hline 0 & 1243 & 44 & 1121 & 44 & 122 & 46 & \\
\hline 1 & 634 & 23 & 587 & 23 & 47 & 18 & \\
\hline $2+$ & 922 & 33 & 826 & 33 & 96 & 36 & \\
\hline \multicolumn{7}{|l|}{ ASA score } & 0.17 \\
\hline I-II & 1942 & 70 & 1768 & 70 & 174 & 66 & \\
\hline III+ & 838 & 30 & 749 & 30 & 89 & 34 & \\
\hline \multicolumn{8}{|l|}{ Unknown } \\
\hline \multicolumn{7}{|l|}{ Location of tumor } & $<0.001$ \\
\hline Esophageal-gastric junction/fundus & 313 & 12 & 286 & 12 & 27 & 11 & \\
\hline Corpus & 833 & 31 & 775 & 31 & 58 & 23 & \\
\hline Antrum/pylorus & 1330 & 49 & 1214 & 49 & 116 & 45 & \\
\hline Entire stomach & 141 & 5 & 94 & 4 & 47 & 18 & \\
\hline Pouch/anastomosis & 109 & 4 & 99 & 4 & 10 & 4 & \\
\hline Unknown & 0 & 0 & 0 & 0 & 0 & 0 & \\
\hline \multicolumn{7}{|l|}{ Clinical tumor category } & $<0.001$ \\
\hline сT0-2 & 825 & 30 & 781 & 31 & 44 & 17 & \\
\hline cT3 & 1177 & 43 & 1041 & 42 & 136 & 52 & \\
\hline cT4 & 152 & 6 & 128 & 5 & 24 & 9 & \\
\hline cTx & 602 & 22 & 542 & 22 & 60 & 23 & \\
\hline Missing & 0 & 0 & 0 & 0 & 0 & 0 & \\
\hline \multicolumn{7}{|l|}{ Clinical node category } & 0.007 \\
\hline cNO & 1433 & 52 & 1319 & 53 & 114 & 43 & \\
\hline $\mathrm{cN}+$ & 1038 & 38 & 925 & 37 & 113 & 43 & \\
\hline $\mathrm{cNx}$ & 288 & 10 & 251 & 10 & 37 & 14 & \\
\hline Missing & 0 & 0 & 0 & 0 & 0 & 0 & \\
\hline \multicolumn{7}{|l|}{ Clinical metastases category } & 0.043 \\
\hline cM-0 & 2618 & 94 & 2375 & 94 & 243 & 92 & \\
\hline $\mathrm{cM}+$ & 44 & 2 & 35 & 1 & 9 & 3 & \\
\hline $\mathrm{cMx}$ & 137 & 5 & 124 & 5 & 13 & 5 & \\
\hline \multicolumn{7}{|l|}{ Tumor histology } & 0.092 \\
\hline Adenocarcinoma & 2633 & 95 & 2379 & 95 & 254 & 97 & \\
\hline Squamous carcinoma & 5 & 0 & 5 & 0 & 0 & 0 & \\
\hline Other & 133 & 5 & 127 & 5 & 6 & 2 & \\
\hline Not applicable & 3 & 0 & 2 & 0 & 1 & 0 & \\
\hline Unknown & 0 & 0 & 0 & 0 & 0 & 0 & \\
\hline \multicolumn{7}{|l|}{ Histological subtype } & $<0.001$ \\
\hline Intestinal adenocarcinoma & 1149 & 41 & 1097 & 43 & 52 & 20 & \\
\hline Diffuse adenocarcinoma & 823 & 29 & 676 & 27 & 147 & 56 & \\
\hline
\end{tabular}


TABLE 1 continued

\begin{tabular}{|c|c|c|c|c|c|c|c|}
\hline \multirow[t]{3}{*}{ Patient characteristics } & \multirow{2}{*}{\multicolumn{2}{|c|}{$\begin{array}{l}\text { Total } \\
n=2799\end{array}$}} & \multirow{2}{*}{\multicolumn{2}{|c|}{$\begin{array}{l}\text { Complete tumor removal } \\
n=2534(90.5 \%) \\
\end{array}$}} & \multirow{2}{*}{\multicolumn{2}{|c|}{$\begin{array}{l}\text { Incomplete tumor removal } \\
n=265(9.5 \%)\end{array}$}} & \multirow[t]{3}{*}{$P$ value } \\
\hline & & & & & & & \\
\hline & $n$ & $\%$ & $n$ & $\%$ & $n$ & $\%$ & \\
\hline Mixed type & 164 & 6 & 153 & 6 & 11 & 4 & \\
\hline Unknown & 663 & 24 & 608 & 24 & 55 & 21 & \\
\hline Differentiation grade & & & & & & & $<0.001$ \\
\hline Well/moderate & 881 & 32 & 835 & 33 & 46 & 17 & \\
\hline Poor/undifferentiated & 1471 & 53 & 1273 & 50 & 198 & 75 & \\
\hline Not available & 93 & 3 & 91 & 4 & 2 & 1 & \\
\hline Unknown & 354 & 13 & 335 & 13 & 19 & 7 & \\
\hline Pathological tumor stage & & & & & & & $<0.001$ \\
\hline pT0-2 & 1030 & 37 & 1010 & 40 & 20 & 8 & \\
\hline pT3 & 1094 & 40 & 977 & 39 & 117 & 45 & \\
\hline pT4 & 614 & 22 & 490 & 20 & 124 & 47 & \\
\hline $\mathrm{pTx}$ & 32 & 1 & 30 & 1 & 2 & 1 & \\
\hline Missing & 0 & 0 & 0 & 0 & 0 & 0 & \\
\hline Pathological node stage & & & & & & & $<0.001$ \\
\hline pNO & 1254 & 45 & 1198 & 48 & 56 & 21 & \\
\hline $\mathrm{pN}+$ & 1481 & 53 & 1277 & 51 & 204 & 78 & \\
\hline $\mathrm{pNx}$ & 36 & 1 & 33 & 1 & 3 & 1 & \\
\hline Missing & 0 & 0 & 0 & 0 & 0 & 0 & \\
\hline Pathological metastases stage & & & & & & & $<0.001$ \\
\hline pM0 & 2490 & 89 & 2272 & 90 & 218 & 82 & \\
\hline pM1 & 118 & 4 & 89 & 4 & 29 & 11 & \\
\hline $\mathrm{pMx}$ & 54 & 2 & 47 & 2 & 7 & 3 & \\
\hline Not applicable & 137 & 5 & 126 & 5 & 11 & 4 & \\
\hline$c T$ versus $p T$ staging & & & & & & & 0.019 \\
\hline Correct estimated & 549 & 20 & 509 & 20 & 40 & 15 & \\
\hline Underestimated $\mathrm{T}$ stage & 256 & 9 & 218 & 9 & 38 & 14 & \\
\hline Overestimated $\mathrm{T}$ stage & 72 & 3 & 68 & 3 & 4 & 2 & \\
\hline $\mathrm{cTx}$ & 283 & 10 & 256 & 10 & 27 & 10 & \\
\hline $\mathrm{pTx}$ & 21 & 1 & 20 & 1 & 1 & 0 & \\
\hline $\mathrm{cT}$ or $\mathrm{pT}$ missing & 0 & 0 & 0 & 0 & 0 & 0 & \\
\hline Not applicable (neoadjuvant therapy) & 1585 & 57 & 1431 & 57 & 154 & 58 & \\
\hline
\end{tabular}

ASA American Society of Anesthesiologists

was 70 years [interquartile range: $62-77$ ]. In 265 patients (9.5\%), the tumor was not completely removed. Patient and tumor characteristics according to resection status are shown in Table 1.

Tumor location, histological subtype, and differentiation grade were statistically significant different between patient with complete or incomplete tumor removal. Clinical and pathological $T-, N$ - and $M$-stage was more advanced in patients with incomplete tumor removal.

\section{Risk Factors for Incomplete Tumor Removal}

A tumor located in the entire stomach (versus gastroesophageal junction/fundus), higher cT-categories (cT3, cT4 and cTx category versus cT0-2), a pN+-category and $\mathrm{pNx}$ category (versus $\mathrm{pN}-$ ), and diffuse or unknown type adenocarcinoma (versus intestinal type) were associated with incomplete tumor removal (Table 2). Unknown differentiation grade was associated with a complete tumor removal (compared with poor differentiation grade/undifferentiated). The area under the ROC of the multivariate model was 0.76 . 
TABLE 2 Probability for incomplete tumor removal, results of uni- and multi-variable analyses

\begin{tabular}{|c|c|c|c|c|c|c|}
\hline \multirow{2}{*}{$\begin{array}{l}\text { Probability for incomplete tumor removal } \\
\text { Variables }\end{array}$} & \multicolumn{3}{|c|}{ Univariable analysis } & \multicolumn{3}{|c|}{ Multivariable analysis } \\
\hline & $n$ & OR $[95 \% \mathrm{CI}]$ & $P$ value & $n$ & OR $[95 \% \mathrm{CI}]$ & $P$ value \\
\hline Total & 2799 & & & 2671 & & \\
\hline Age (year) & & & 0.143 & & & \\
\hline $0-64$ & 888 & 1 & & & & \\
\hline $65-74$ & 959 & $0.73[0.54-1]$ & 0.050 & & & \\
\hline $75+$ & 952 & $0.84[0.62-1.14]$ & 0.263 & & & \\
\hline Charlson score & & & 0.121 & & & \\
\hline 0 & 1243 & 1 & & & & \\
\hline 1 & 634 & $0.74[0.52-1.05]$ & 0.087 & & & \\
\hline $2+$ & 922 & $1.07[0.81-1.42]$ & 0.648 & & & \\
\hline ASA score & & & 0.170 & & & \\
\hline $\mathrm{I} / \mathrm{II}$ & 1942 & 1 & & & & \\
\hline $\mathrm{III}+$ & 838 & $1.21[0.92-1.58]$ & & & & \\
\hline Tumor location & & & $<0.001$ & & & $<0.001$ \\
\hline GEJ/Fundus & 313 & 1 & & 304 & 1 & \\
\hline Corpus & 833 & 0.79 [0.49-1.28] & 0.339 & 813 & $0.70[0.43-1.16]$ & 0.167 \\
\hline Antrum/pylorus & 1330 & $1.01[0.65-1.57]$ & 0.957 & 1308 & $0.95[0.60-1.50]$ & 0.828 \\
\hline Entire stomach & 141 & $5.30[3.13-8.98]$ & $<0.001$ & 138 & 3.38 [1.91-5.96] & $<0.001$ \\
\hline Pouch/residual stomach & 109 & $5.30[3.13-8.98]$ & 0.862 & 108 & $1.14[0.51-2.57]$ & 0.749 \\
\hline Clinical tumor category & & & $<0.001$ & & & 0.005 \\
\hline cT0-2 & 825 & 1 & & 808 & 1 & \\
\hline cT3 & 1177 & $2.32[1.63-3.30]$ & $<0.001$ & 1137 & $1.75[1.20-2.56]$ & 0.004 \\
\hline cT4 & 152 & $3.33[1.96-5.66]$ & $<0.001$ & 146 & $2.63[1.47-4.70]$ & 0.001 \\
\hline cTx & 602 & $1.97[1.31-2.94]$ & 0.001 & 580 & $1.60[1.03-2.48]$ & 0.036 \\
\hline Pathological node category & & & $<0.001$ & & & $<0.001$ \\
\hline $\mathrm{pN}-$ & 1254 & 1 & & 1207 & 1 & \\
\hline $\mathrm{pN}+$ & 1481 & $3.42[2.52-4.64]$ & $<0.001$ & 1433 & $2.73[1.96-3.80]$ & $<0.001$ \\
\hline $\mathrm{pNx}$ & 36 & $1.95[0.58-6.53]$ & 0.282 & 31 & $3.17[0.86-11.61]$ & 0.082 \\
\hline Clinical metastases category & & & 0.053 & & & 0.984 \\
\hline $\mathrm{cM} 0$ & 2618 & 1 & & 2517 & 1 & \\
\hline $\mathrm{cM} 1$ & 44 & $2.51[1.19-5.29]$ & 0.015 & 43 & $1.08[0.46-2.51]$ & 0.867 \\
\hline $\mathrm{cMx}$ & 137 & $1.03[0.57-1.84]$ & 0.935 & 111 & $1.02[0.53-1.99]$ & 0.948 \\
\hline Histological subtype & & & $<0.001$ & & & $<0.001$ \\
\hline Intestinal adenocarcinoma & 1149 & 1 & & 1112 & 1 & \\
\hline Diffuse adenocarcinoma & 823 & 4.59 [3.30-6.38] & $<0.001$ & 797 & 3.15 [2.14-4.64] & $<0.001$ \\
\hline Mixed type & 164 & $1.52[0.77-2.97]$ & 0.224 & 160 & $1.02[0.50-2.06]$ & 0.963 \\
\hline Unknown & 663 & $1.91[1.29-2.82]$ & 0.001 & 602 & $2.05[1.34-3.13]$ & 0.001 \\
\hline Differentiation grade & & & $<0.001$ & & & 0.017 \\
\hline Well/moderate & 881 & $0.35[0.25-0.49]$ & & 839 & $0.72[0.48-1.06]$ & \\
\hline Poor/undifferentiated & 1471 & 1 & $<0.001$ & 1417 & 1 & 0.096 \\
\hline Not applicable & 93 & $0.14[0.04-0.58]$ & 0.006 & 89 & $0.33[0.08-1.38]$ & 0.129 \\
\hline Unknown & 354 & $0.37[0.22-0.59]$ & $<0.001$ & 326 & $0.50[0.30-0.83]$ & 0.008 \\
\hline
\end{tabular}


TABLE 2 continued

\begin{tabular}{|c|c|c|c|c|c|c|}
\hline \multirow{2}{*}{$\begin{array}{l}\text { Probability for incomplete tumor removal } \\
\text { Variables }\end{array}$} & \multicolumn{3}{|c|}{ Univariable analysis } & \multicolumn{3}{|c|}{ Multivariable analysis } \\
\hline & $n$ & OR $[95 \% \mathrm{CI}]$ & $P$ value & $n$ & OR $[95 \% \mathrm{CI}]$ & $P$ value \\
\hline Year of resection & & & 0.562 & & & \\
\hline 2011 & 250 & 1 & & & & \\
\hline 2012 & 319 & $0.71[0.42-1.20]$ & 0.199 & & & \\
\hline 2013 & 448 & $0.71[0.43-1.15]$ & 0.160 & & & \\
\hline 2014 & 498 & $0.78[0.49-1.25]$ & 0.294 & & & \\
\hline 2015 & 419 & 0.66 [0.40-1.09] & 0.104 & & & \\
\hline 2016 & 475 & $0.64[0.39-1.05]$ & 0.078 & & & \\
\hline 2017 & 390 & $0.61[0.36-1.02]$ & 0.061 & & & \\
\hline
\end{tabular}

ASA American Society of Anesthesiologists

\section{Hospital Volume}

In Fig. 2, the centralization of gastric surgery in the Netherlands is shown. Compared with 2011, the hospital volumes were higher in 2017, and the number of hospitals performing gastric surgery decreased.

In all logistic regression models, annual hospital volume of $<20$ was associated with a higher percentage of incomplete tumor removal compared to annual hospital volumes of 20-39 and $\geq 40$ resections per year (Table 3). There was no statistically significant difference between 20-39 and $\geq 40$ resections per year. In a sensitivity analysis including data from the period 2014-2017, similar results were found (data not shown). In stratified analyses according to neo-adjuvant therapy, similar results were found. Patients not treated with neo-adjuvant therapy, with a volume of $<20$ resections/year had a higher probability for incomplete tumor resection compared to 20-39 resections/year and 40 or more resections/year (OR: 0.60 [0.37-0.98] and 0.19 [0.05-0.69], respectively). In patients treated with neo-adjuvant therapy, the probability for incomplete tumor resection also was higher for low hospital volume $(<20$ resections/year $)$ compared with 20-39 resections/year (OR: 0.65 [0.43-0.98]) and for 40 or more resections/year (OR 0.50 [0.23-1.09]).

\section{Site of Tumor-Positive Margin}

In 175 of 265 patients with incomplete tumor removal, the site of the tumor-positive resection margin was reported in the DUCA (Supplementary Table 1). When the resection of the tumor was incomplete, the proximal resection margin was mostly involved in patients with proximal gastric cancer (junctional/fundus $86 \%$ and corpus $80 \%$ ). Gastrectomy for distal tumors (antrum/pylorus) was most often incomplete at the distal margin $(68 \%)$. When the tumor was located in the entire stomach, the resection was incomplete at the distal margin in $17 \%$, the proximal margin in $42 \%$, and involvement of both margins was seen in $42 \%$ of patients (Supplementary Table 2).

\section{DISCUSSION}

This Dutch cohort study shows that patients with advanced gastric cancers (i.e., involving the entire stomach, advanced TNM-stage, and diffuse-type gastric cancer) are at risk for incomplete tumor removal. Furthermore, low annual hospital volume $(<20$ resections per year) also is associated with a higher risk for incomplete tumor removal than middle and high-volume hospitals. The present study is the first population-based study reporting patient-related and tumor-related factors associated with incomplete tumor removal for gastric cancer. The risk factors that were identified in this national cohort study are similar to earlier studies: Songun et al. ${ }^{17}$ reported the association between incomplete tumor removal with tumor location and size of the tumor. Other studies reported the association between incomplete tumor removal and diffuse type carcinoma. ${ }^{18,19}$ The risk factors identified in the present study appear to be related to more advanced stomach cancer, and this in itself might be a risk factor for an incomplete tumor removal.

In addition to patient and tumor factors, Bissolati et al. studied the association between the distance from the tumor to the margin of resection and incomplete tumor removal. They showed that resection margins of $<20 \mathrm{~mm}$ in $\mathrm{T} 1$ tumors resection and resection margins of $<30 \mathrm{~mm}$ in and T2-4 tumors were associated with incomplete tumor removal. ${ }^{7}$ In the present study, the association of resection margin with incomplete tumor removal could not be assessed. Based on the study by Bissolati et al., it could be argued that an extra wide resection margin may prevent incomplete tumor removal. The Dutch guideline recommends a minimum resection margin of $60 \mathrm{~mm} .{ }^{6}$ The 


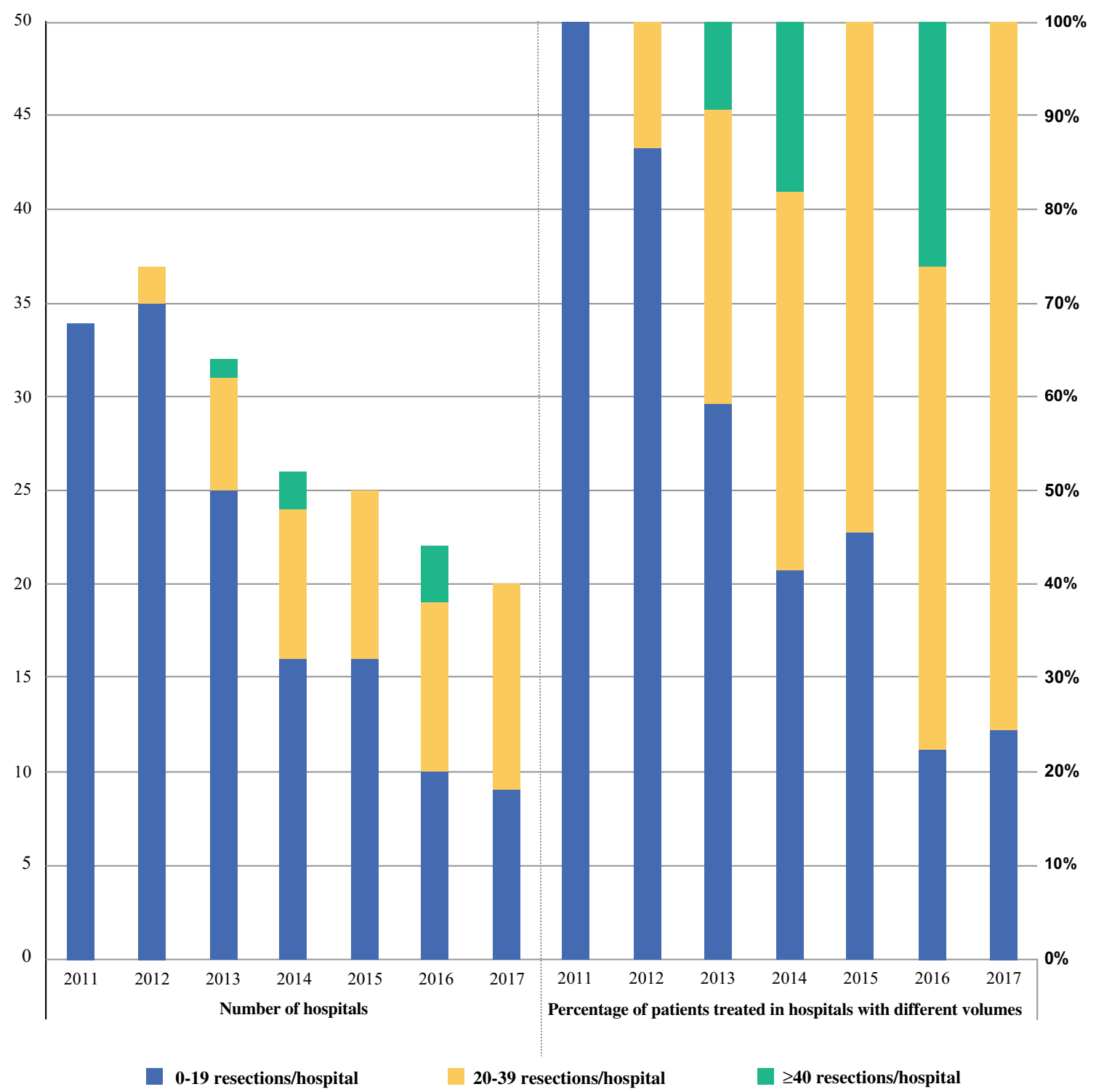

FIG. 2 Centralization gastric cancer surgery

German guideline recommends a resection margin of $50 \mathrm{~mm}$ for intestinal type and $80 \mathrm{~mm}$ for diffuse-type gastric cancer. ${ }^{20}$

Choosing an appropriate surgical margin can be challenging. The margin should be wide enough to prevent incomplete tumor removal but at the same time a technically feasible and reliable reconstruction should be created. To achieve a safe proximal resection margin for middle gastric tumors, a total gastrectomy may be indicated. Although postoperative mortality and 5-year survival after total and subtotal gastrectomy is comparably, a subtotal gastrectomy is associated with less nutritional side effects and a better quality of life. ${ }^{21}$
For proximal gastric tumors that invade the esophagus, a more technically challenging anastomosis in the lower mediastinum or a total gastrectomy with subtotal esophagectomy and colonic interposition may be indicated. This procedures have a higher risk for anastomotic leakage or other postoperative complications. ${ }^{22,23}$

Bissolati et al. also showed that there was an association between incomplete tumor removal at the esophagogastric junction. However, the surgeon may be confronted intraoperatively with a difficult decision as how to deal with suspicious extension of the tumor beyond what was anticipated. Proximal gastric cancers may invade the esophagus and the proximal resection margin is at risk. 
TABLE 3 Multiple regression models to test the association of hospital volume with incomplete tumor removal

\begin{tabular}{|c|c|c|c|c|c|c|c|}
\hline \multicolumn{2}{|l|}{$\begin{array}{l}\text { Probability for incomplete tumor removal based on patient and tumor } \\
\text { characteristics } \\
2011-2017\end{array}$} & \multirow{3}{*}{$\begin{array}{l}n \\
\\
2671\end{array}$} & \multirow[t]{2}{*}{ OR } & \multirow[t]{2}{*}{$95 \% \mathrm{CI}$} & \multirow[t]{2}{*}{$P$ value } & \multirow{2}{*}{$\begin{array}{l}\text { Nagelkerke } \\
R^{2} \\
0.17\end{array}$} & \multirow{2}{*}{$\begin{array}{l}\text { ROC } \\
0.76\end{array}$} \\
\hline & Total & & & & & & \\
\hline \multicolumn{6}{|l|}{$\begin{array}{l}\text { Patient and tumor factors added to the model: location tumor, cT } \\
\text { category, pN stage, cM category, histological subtype, } \\
\text { differentiation grade }\end{array}$} & & \\
\hline Hospital volume & & & & & 0.001 & & \\
\hline \multirow[t]{3}{*}{ Not adjusted } & $\begin{array}{l}<20 \\
\text { resections/ } \\
\text { year }\end{array}$ & 1388 & 1 & & & & \\
\hline & $\begin{array}{l}\text { 20-39 } \\
\text { resections/ } \\
\text { year }\end{array}$ & 1155 & 0.68 & {$[0.52-0.89]$} & 0.004 & & \\
\hline & $\begin{array}{l}40 \text { or more } \\
\text { resections/ } \\
\text { year }\end{array}$ & 256 & 0.41 & {$[0.23-0.74]$} & 0.003 & & \\
\hline Hospital volume & & & & & $<0.001$ & & \\
\hline \multirow[t]{3}{*}{$\begin{array}{l}\text { Adjusted for: location tumor, cT category, } \mathrm{pN} \text { stage, cM category, } \\
\text { histological subtype, differentiation grade }\end{array}$} & $\begin{array}{l}<20 \\
\text { resections/ } \\
\text { year }\end{array}$ & 1308 & 1 & & & & \\
\hline & $\begin{array}{l}\text { 20-39 } \\
\text { resections/ } \\
\text { year }\end{array}$ & 1134 & 0.56 & {$[0.42-0.76]$} & $<0.001$ & & \\
\hline & $\begin{array}{l}40 \text { or more } \\
\text { resections/ } \\
\text { year }\end{array}$ & 229 & 0.34 & {$[0.18-0.64]$} & 0.001 & & \\
\hline Hospital volume (other reference) & & & & & $<0.001$ & & \\
\hline \multirow[t]{3}{*}{$\begin{array}{l}\text { Adjusted for: location tumor, cT category, } \mathrm{pN} \text { stage, cM category, } \\
\text { histological subtype, differentiation grade }\end{array}$} & $\begin{array}{l}<20 \\
\text { resections/ } \\
\text { year }\end{array}$ & 1308 & 2.95 & {$[1.57-5.55]$} & 0.001 & & \\
\hline & $\begin{array}{l}\text { 20-39 } \\
\text { resections/ } \\
\text { year }\end{array}$ & 1134 & 1.66 & {$[0.88-3.13]$} & 0.120 & & \\
\hline & $\begin{array}{l}40 \text { or more } \\
\text { resections/ } \\
\text { year }\end{array}$ & 229 & 1 & & & & \\
\hline
\end{tabular}

In the present study, tumor location was not associated with incomplete tumor removal. Distal gastric cancers may invade the duodenum and a Whipple's operation for patients who can tolerate this should be considered. In the Netherlands, the foundation for oncological cooperation (SONCOS) recommends that gastric and esophageal resections should be performed in the same hospital. ${ }^{24}$ However, there are no recommendations regarding the combination of gastric and hepatobiliary surgery. ${ }^{25}$ Therefore, when it is anticipated that the proximal margin at the esophagus or the duodenum is at risk, it is probably advisable to refer patients to hospitals where esophageal and/or hepatobiliary surgery is performed.

To facilitate a radical resection without unnecessarily wide resection margins, intraoperative frozen-section analysis could be used. However, this technique is time- consuming, and the clinical value can be dubious since results can be false negative. ${ }^{26,27}$ Squires et al. evaluated outcomes of patients with gastric cancer with a positive intraoperative proximal frozen section converted to an R0 resection in the same procedure. The local recurrence was significantly lower in the converted-to-R0 group than in patients with a positive final frozen section. This study showed that overall survival and progression-free survival was not improved. ${ }^{28}$ If time is a concern of hospitals, a frozen section could be considered to achieve a $R 0$ resection in high-risk patients as identified in this study rather than in all patients.

Additionally, intraoperative endoscopic ultrasonography may help to determine the extent of infiltration in the esophagus or duodenum. ${ }^{29}$ Kawakatsu et al. described the combination of preoperative placement of marking clips 
and intraoperative endoscopy as being helpful to determine a surgical margin in patients who undergo laparoscopic gastrectomy. However, this is the only study that describes the systematical use of endoscopy during gastrectomy. Further studies are needed to evaluate the benefits of this technique.

Besides tumor-related factors, the surgeon's experience with esophageal and gastric cancer surgery and the number of operations per year performed (hospital volume) may be important to reduce the number of incomplete resections. In the present study, a hospital volume of $<20$ gastric resections per year was associated with a higher chance of incomplete tumor removal compared with 20-50 and $>50$ resections per year. In the past, the association between hospital volume and postoperative morbidity/mortality and overall survival has been studied..$^{8-10,30-33}$ For overall survival, conflicting results were published. However, for postoperative morbidity and mortality, several studies reported improved outcomes in high-volume centers. More recently, low hospital volume $(<25$ resections per year) was associated with fewer retrieved lymph nodes. ${ }^{34}$ Between 2012 and 2014, the Association of Surgeons of the Netherlands introduced volume standards for complex surgery. In particular for gastric surgery, a minimum volume of 10 gastric cancer resections in 2012, and from 2013 onwards a minimum of 20 resections per year was required. Currently, some Dutch hospitals have not met this standard yet, and centralization in gastric surgery is still ongoing (Fig. 2). It may be possible that hospitals with a relatively low number of patients with gastric cancer use more liberal criteria to select patients for gastrectomy to comply with the minimum required target. This may result in worse outcomes, e.g., higher rates of incomplete tumor removal. At present, we are performing a more in-depth examination in several hospitals to identify if organizational, human, or technical factors contribute to unfavorable outcomes after gastrectomy. Nevertheless, the current study endorses the need for centralization of gastric cancer surgery. Another strategy could involve discussing complex patients in a multicenter, multidisciplinary team. ${ }^{35}$

In the case of postoperative determination of tumorpositive resection margins, some studies describe that adjuvant chemoradiotherapy is associated with improved survival, especially for patients who had no neoadjuvant therapy. ${ }^{36-38}$ Another option that may benefit is to perform a reoperation with resection of the tumor-positive resection margins. ${ }^{39,40}$ The largest cohort of reoperations was 122 patients, and a reoperation was successfully performed in $41 \%$ of these patients. The authors of the study describe a survival benefit especially for stage N2 or lower tumors. ${ }^{41}$ However, evidence for an optimal treatment after an incomplete tumor removal is based on nonrandomized studies with small patient groups.
The main strength of this study is the nationwide coverage of the dataset allowing national performance to be assessed. Outcomes of studies using population-based data reflect daily clinical practice. Prospective (randomized) trials are usually conducted under strict quality control and only with selected patients and thus may not reflect the real world. A national registry might do reflect the real world. However, a database from a national registry also may have its disadvantages; the accuracy and completeness of data may be questioned. Nevertheless, we believe that the DUCA database is accurate to answer our research question. The case ascertainment of the DUCA database is estimated at $97.8 \%$, and the resection status is reported with high completeness (1.6\% missing; Fig. 1). ${ }^{13}$ Because in the Netherlands, the information regarding resection margins must be reported according to a standardized pathology report. We assume that the accuracy of the registered resection status also is high. ${ }^{12}$

Another limitation is the retrospective nature of this study. In this study, we could not evaluate the influence of treatment-related factors on resection status, such as neoadjuvant chemotherapy and the surgical approach. The reason for this is that bias in the selection of patients for specific treatments may have occurred (treatment by indication bias). Therefore, this study could not evaluate muchdiscussed, treatment-related factors, such as the approach of surgery. However, recently, a study with data of the DUCA compared minimally invasive gastrectomy with open gastrectomy in a propensity-matched cohort. This study showed no differences in resection status between the two groups ( $R 0$ in $88 \%$ vs. $85 \%, P=0.189) .{ }^{42}$ Another potential treatment-related factor that could not be evaluated in this study is inadequate diagnostic staging. From the present dataset, it was not possible to compare the diagnostic workup between patients who underwent a complete and incomplete tumor removal, because both patient identity and hospital identity are anonymous.

Finally, data on survival were not available. Therefore, evaluation of the (independent) association of complete resection with survival was not possible. A gastrectomy with tumor-positive margins may reflect an aggressive biology of the tumor and as a consequence have a poor prognosis. Even after gastrectomy with negative resection margins, large, poorly differentiated tumors will likely spread beyond the surgical field, and surgery cannot cure these patients. Future studies may be needed to evaluate the independent association of incomplete resections with survival.

ACKNOWLEDGMENT The authors thank all surgeons, registrars, physician assistants, and administrative nurses for data registration in the DUCA database, as well as the Dutch Upper GI Cancer Audit group for scientific input. 


\section{CONFLICT OF INTEREST None declared.}

OPEN ACCESS This article is distributed under the terms of the Creative Commons Attribution 4.0 International License (http://crea tivecommons.org/licenses/by/4.0/), which permits unrestricted use, distribution, and reproduction in any medium, provided you give appropriate credit to the original author(s) and the source, provide a link to the Creative Commons license, and indicate if changes were made.

\section{REFERENCES}

1. Jaehne J, Meyer HJ, Maschek H, Geerlings H, Burns E, Pichlmayr R. Lymphadenectomy in gastric carcinoma. A prospective and prognostic study. Arch Surg. 1992;127:290-294.

2. Ridwelski K, Fahlke J, Huss M, Otto R, Wolff S. [R1 resection for gastric carcinoma]. Chirurg. 2017;88:756-63.

3. DICA (Dutch Institute for Clinical Auditing). Annual report of the Dutch Upper gastrointestinal Cancer Audit 2016. Available: $\mathrm{h}$ ttps://dica.nl/jaarrapportage-2016/duca. Accessed 18 April 2019.

4. Busweiler LAD, Jeremiasen M, Wijnhoven BPL, Lindblad M, Lundell L, van de Velde CJH, et al. International benchmarking in oesophageal and gastric cancer surgery. BJS Open. 2018;3:62-73.

5. Clinical Effectiveness Unit, The Royal College of Surgeons of England. National Oesophago-Gastric Cancer Audit 2016. Available: https://www.nogca.org.uk/. Accessed 19 April 2019.

6. Oncoline. Guideline gastric cancer Version: 2.2. Available: htt p://www.oncoline.nl/maagcarcinoom. Accessed 19 April 2019.

7. Bissolati M, Desio M, Rosa F, et al. Risk factor analysis for involvement of resection margins in gastric and esophagogastric junction cancer: an Italian multicenter study. Gastric Cancer. 2017;20:70-82.

8. Dikken JL, Dassen AE, Lemmens VE, et al. Effect of hospital volume on postoperative mortality and survival after oesophageal and gastric cancer surgery in the Netherlands between 1989 and 2009. Eur J Cancer. 2012;48:1004-13.

9. Anderson O, Ni Z, Moller H, et al. Hospital volume and survival in oesophagectomy and gastrectomy for cancer. Eur J Cancer. 2011;47:2408-14.

10. Coupland VH, Lagergren J, Luchtenborg M, et al. Hospital volume, proportion resected and mortality from oesophageal and gastric cancer: a population-based study in England, 2004-2008. Gut. 2013;62:961-6.

11. Kauppila JH, Wahlin K, Lagergren P, Lagergren J. University hospital status and surgeon volume and risk of reoperation following surgery for esophageal cancer. Eur J Surg Oncol. 2018;44:632-7.

12. The nationwide network and registry of histo- and cytopathology in the Netherlands (PALGA Foundation). National Protocol Esophageal/Gastric Carcinoma version18. Available: https://ww w.palga.nl/en/assets/uploads/Protocollen/Maag-Oesofaguscarcin oom.pdf. Accessed 18 April 2019.

13. Busweiler LA, Wijnhoven BP, van Berge Henegouwen MI, et al. Early outcomes from the Dutch Upper Gastrointestinal Cancer Audit. Br J Surg. 2016;103:1855-63.

14. Siewert JR, Stein HJ. Classification of adenocarcinoma of the oesophagogastric junction. Br J Surg. 1998;85:1457-9.

15. College of American Pathologists. Protocol for the examination of specimens from patients with carcinoma of the stomach. In: Protocol applies to all invasive carcinomas of the stomach Tumors of the esophagogastric junction and well-differentiated neuroendocrine tumors (carcinoid tumors) are not included. College of American Pathologists; 2013.
16. Charlson ME, Pompei P, Ales KL, MacKenzie CR. A new method of classifying prognostic comorbidity in longitudinal studies: development and validation. $J$ Chronic Dis. 1987;40:373-83.

17. Songun I, Bonenkamp JJ, Hermans J, van Krieken JH, van de Velde CJ. Prognostic value of resection-line involvement in patients undergoing curative resections for gastric cancer. Eur $J$ Cancer. 1996;32a:433-7.

18. Stiekema J, Cats A, Kuijpers A, et al. Surgical treatment results of intestinal and diffuse type gastric cancer. Implications for a differentiated therapeutic approach? Eur J Surg Oncol. 2013;39:686-93.

19. Blackham AU, Swords DS, Levine EA, et al. Is linitis plastica a contraindication for surgical resection: a multi-institution study of the U.S. Gastric Cancer Collaborative. Ann Surg Oncol. 2016;23:1203-11.

20. Moehler M, Al-Batran SE, Andus T, et al. [German S3-guideline "Diagnosis and treatment of esophagogastric cancer"]. Z Gastroenterol. 2011;49:461-531.

21. Gouzi JL, Huguier M, Fagniez PL, et al. Total versus subtotal gastrectomy for adenocarcinoma of the gastric antrum. A French prospective controlled study. Ann Surg. 1989;209:162-6.

22. Brown J, Lewis WG, Foliaki A, Clark GWB, Blackshaw G, Chan DSY. Colonic interposition after adult oesophagectomy: systematic review and meta-analysis of conduit choice and outcome. J Gastrointest Surg. 2018;22:1104-11.

23. Kurokawa Y, Sasako M, Sano T, et al. Functional outcomes after extended surgery for gastric cancer. Br J Surg. 2011;98:239-45.

24. SONCOS (Stichting Oncologische Samenwerking). Multidisciplinaire Normering Oncologische Zorg in Nederland 2016. Available: https://www.soncos.org/kwaliteit/normeringsrapport/. Accessed 18 April 2019.

25. Leitlinien Programm Onkologie . Magenkarzinom "Diagnostik und Therapie der Adenokarzinome des Magens und ösophagogastralen Übergangs.” Available: https://www.leitlinienprogra mm-onkologie.de/fileadmin/user_upload/Downloads/Leitlinien/ Magenkarzinom/S3-Magenkarzinom-OL-Langversion.pdf. Accessed 18 April 2019.

26. Shen JG, Cheong JH, Hyung WJ, Kim J, Choi SH, Noh SH. Intraoperative frozen section margin evaluation in gastric cancer of the cardia surgery. Hepatogastroenterology. 2006;53:976-8.

27. DiNardo LJ, Lin J, Karageorge LS, Powers CN. Accuracy, utility, and cost of frozen section margins in head and neck cancer surgery. Laryngoscope. 2000;110:1773-6.

28. Squires MH, 3rd, Kooby DA, Pawlik TM, et al. Utility of the proximal margin frozen section for resection of gastric adenocarcinoma: a 7-Institution Study of the US Gastric Cancer Collaborative. Ann Surg Oncol. 2014;21:4202-10.

29. Kawakatsu S, Ohashi M, Hiki N, Nunobe S, Nagino M, Sano T. Use of endoscopy to determine the resection margin during laparoscopic gastrectomy for cancer. $\mathrm{Br} \quad J$ Surg. 2017; 104:1829-36.

30. Enzinger PC, Benedetti JK, Meyerhardt JA, et al. Impact of hospital volume on recurrence and survival after surgery for gastric cancer. Ann Surg. 2007;245:426-34.

31. Damhuis RAM, Meurs CJC, Dijkhuis CM, Stassen LPS, Wiggers T. Hospital volume and post-operative mortality after resection for gastric cancer. Eur J Surg Oncol. 2002;28:401-5.

32. Smith DL, Elting LS, Learn PA, Raut CP, Mansfield PF. Factors influencing the volume-outcome relationship in gastrectomies: a population-based study. Ann Surg Oncol. 2007;14:1846-52.

33. Busweiler LA, Dikken JL, van Berge Henegouwen MI, et al. The influence of a composite hospital volume of upper gastrointestinal cancer resections on outcomes of gastric cancer surgery. J Clin Oncol. 2016;34:305. 
34. van der Werf LR, Dikken JL, van Berge Henegouwen MI, Lemmens V, Nieuwenhuijzen GAP, Wijnhoven BPL. A population-based study on lymph node retrieval in patients with esophageal cancer: results from the dutch upper gastrointestinal cancer audit. Ann Surg Oncol. 2018;25:1211-20.

35. van Putten M, Verhoeven RH, van Sandick JW, et al. Hospital of diagnosis and probability of having surgical treatment for resectable gastric cancer. Br J Surg. 2016;103:233-41.

36. Dikken JL, Jansen EP, Cats A, et al. Impact of the extent of surgery and postoperative chemoradiotherapy on recurrence patterns in gastric cancer. J Clin Oncol. 2010;28:2430-6.

37. Stiekema J, Trip AK, Jansen EP, et al. Does adjuvant chemoradiotherapy improve the prognosis of gastric cancer after an $\mathrm{r} 1$ resection? Results from a dutch cohort study. Ann Surg Oncol. 2015;22:581-8.

38. Ho VKY, Jansen EPM, Wijnhoven BPL, et al. Adjuvant chemoradiotherapy for non-pretreated gastric cancer. Ann Surg Oncol. 2017;24:3647-57.

39. Liang Y, Ding X, Wang X, et al. Prognostic value of surgical margin status in gastric cancer patients. ANZ $J$ Surg. 2015;85:678-84.
40. Aurello P, Magistri P, Nigri G, et al. Surgical management of microscopic positive resection margin after gastrectomy for gastric cancer: a systematic review of gastric R1 management. Anticancer Res. 2014;34:6283-8.

41. Chen JD, Yang XP, Shen JG, Hu WX, Yuan XM, Wang LB. Prognostic improvement of reexcision for positive resection margins in patients with advanced gastric cancer. Eur J Surg Oncol. 2013;39:229-34.

42. Brenkman HJF, Gisbertz SS, Slaman AE, et al. Postoperative outcomes of minimally invasive gastrectomy versus open gastrectomy during the early introduction of minimally invasive gastrectomy in the NETHERLANDS: a population-based cohort study. Ann Surg. 2017;266:831-838.

Publisher's Note Springer Nature remains neutral with regard to jurisdictional claims in published maps and institutional affiliations. 